\title{
Rantai Nilai Jeruk Keprok (Citrus Reticulate) Soe di Kabupaten Timor Tengah Selatan Provinsi Nusa Tenggara Timur
}

\section{The Soe's Keprok Orange (Citrus Reticulate) Value Chain In South Central Timor Regency East Nusa Tenggara Province}

\author{
Gregorius Gehi Batafor $^{1 *}$ dan Yason Edison Benu ${ }^{2}$ \\ ${ }^{1}$ Program Studi Manajemen Agribisnis Politeknik Pertanian Negeri Kupang \\ ${ }^{2}$ Program Studi Manajemen Pertanian Lahan Kering Politeknik Pertanian Negeri Kupang \\ *E-mail: gregorius.batafor@gmail.com
}

\begin{abstract}
These study aims are analyzed the value chain after applying Soe tangerine cold storage technology. Qualitative and quantitative research methodologies, while data analysis techniques used the biological method and cost analysis. Value chain analysis shows that collectors' profits are IDR 5,306 per $\mathrm{kg}$, retailer IDR 10,806 per $\mathrm{kg}$, while farmers IDR 1,806 per $\mathrm{kg}$. If the difference between each actor in the distribution chain is calculated, the farmer only receives an added value of IDR 2,250 per kg, while collecting traders IDR 5,750 per $\mathrm{kg}$ and retailers IDR 11,250 per $\mathrm{kg}$. The RC ratio produced by farmers is 1.14, collecting traders 1.31, and retailers 1.45. Analysis of basic costs, cold storage for 3 months requires a fee of IDR 708,146 per $\mathrm{kg}$. This value is lower compared to conventional storage of IDR 1,372 per kg. Based on interviews regarding price predictions for the next 3 months and shrinkage values, there is a significant difference between conventional storage and cold storage. The advantage of cold storage is greater than conventional storage, which is IDR 13,417 per $\mathrm{kg}$ while conventional storage is IDR $3000 \mathrm{per} \mathrm{kg}$. The increase was obtained assuming the price before being saved IDR 22,250 per $\mathrm{kg}$, and the sale price after saving is IDR 35,000 per kg. Value chain analysis shows that three stakeholders can use cold storage technology, namely farmers, collectors, and retailers in several people's markets in Kupang City. With the lowest profit and RC value in farmers, cold storage technology is more suitable for farmers compared to other actors. With cold storage technology, the chances of Soe's tangerine offering will remain under control.
\end{abstract}

Keywords: Value Chain, Cold Storage Technology

Disubmit: 02 Oktober 2019; Diterima: 11 November 2019; Disetujui: 10 Desember 2019

\section{PENDAHULUAN}

Jeruk keprok (Citrus reticulate) Soe merupakan icon Kabupaten Timor Tengah Selatan, yang saat ini memiliki banyak persoalan. Pada sentra produksi, petani selalu berada pada posisi yang lemah dikarenakan harga yang rendah bila ingin cepat terjual atau akan mengalami susut bila ingin disimpan. Tingginya harga jeruk pada tingkat pengecer di pasar, ternyata tidak terdistribusi dengan baik ke tingkat petani sehingga petani sebagai produsen hanya memperoleh porsi pendapatan terkecil dan selalu fluktuatif. 
Dari sisi konsumen, jeruk hanya dibutuhkan dalam jumlah sedikit tetapi selalu kontinu. Apabila tidak dilakukan distribusi penawaran dengan baik, dapat mengakibatkan kelangkaan suplai di pasaran ketika tidak pada masa panen, apalagi mengingat tingginya angka penyusutan dan kerusakan (karakteristik komoditas pertanian yang pada umumnya perishable dan fragile). Pada kondisi ini, pedagang pengepul maupun pengecer akan mendatangkan jeruk dari daerah luar seperti Malang dan Bali untuk dapat memenuhi permintaan masyarakat. Persoalan ini mungkin dapat dicarikan alternatif pemecahannya, mengingat jumlah produksi jeruk keprok Soe sebenarnya lebih besar daripada jumlah konsumsi masyarakat terhadap komoditi jeruk di wilayah NTT.

Persoalan penyusutan dan tingkat kerusakan hasil panen petani jeruk dapat diminimalisir dengan adanya proses penanganan pasca panen berupa penyimpanan yang baik sehingga mampu menyelamatkan surplus produksi jeruk dan dapat mencegah rendahnya harga jual di pasaran yang tentunya sangat merugikan para petani jeruk keprok Soe itu sendiri.

Teknologi penyimpanan menjadi hal krusial dalam mengendalikan pasokan jeruk keprok Soe dan berpotensi meningkatkan nilai tambah. Penyimpanan yang baik dapat memperpanjang umur simpan sehingga mengurangi tingkat penyusutan dan kerusakan pada saat panen raya dan menggunakannya pada saat kekurangan. Analisis rantai nilai dilakukan untuk menjelaskan tingkat keuntungan yang diperoleh masing-masing stakeholder di dalam rantai nilai jeruk keprok Soe, sehingga dapat dijadikan informasi awal tentang stakeholder mana yang perlu melakukan perbaikan input dengan penerapan teknologi penyimpanan dingin untuk dapat meningkatkan nilai tambah produknya (Kotler, P. \& Armstrong, 2008). Pendekatan rantai nilai membantu memahami bagaimana kondisi membentuk rantai nilai, melakukan identifikasi siapa yang menanganinya, menjawab pertanyaan yang luas, spesifik, dan dapat melakukan pendekatan membangun hubungan kemitraan (Bahtiar J, 2011).

\section{METODE PENELITIAN}

Penelitian dilakukan di Kabupaten Timor Tengah Selatan Provinsi Nusa Tenggara Timur pada bulan Maret sampai bulan Oktober tahun 2019. Pemilihan lokasi dilakukan secara sengaja (purposive), dengan pertimbangan bahwa kabupaten tersebut merupakan sentra produksi jeruk keprok di Provinsi Nusa Tenggara Timur. Penelitian rantai distribusi dilakukan mulai dari petani, pedagang pengumpul dan pedagang pengecer dan konsumen akhir pada beberapa pasar induk di Kota Kupang.

Data primer bersumber dari petani jeruk keprok Soe mengenai luas tanam, biaya produksi, jumlah produksi, jumlah susut di setiap tindakan pascapanen dan harga jual. Data primer yang diperoleh dari pedagang pengumpul dan pedagang pengecer berupa biaya pembelian, biaya transportasi, susut transportasi, susut persediaan barang dagangan, biaya tenaga kerja, biaya storage, biaya sewa lapak dan biaya overhead lainnya. Data sekunder diperoleh dari laporan instansi pemerintah dan berbagai literatur pendukung lainnya.

Fokus penelitian dibagi menjadi tiga aktivitas yaitu (1) menganalisis rantai nilai dalam setiap rantai distribusi; (2) membandingkan tingkat keuntungan yang diperoleh oleh masing-masing stakeholders agar dapat menentukan stakeholder mana tepat untuk menerapkan teknologi penyimpanan pada rantai distribusi; dan (3) mengkaji dan membandingkan nilai tambah akibat penerapan teknologi penyimpanan dingin dengan teknik penyimpanan konvensional yang selama ini sudah diterapkan. Analisis nilai tambah menggunakan metode Hayami (Tabel 1). Data-data yang diperlukan untuk menghitung nilai tambah berupa jumlah output, bahan baku dan tenaga kerja per periode, data harga output, upah rata-rata, harga bahan baku dan biaya sumbangan input lainnya. Langkah-langkah dalam analisis nilai tambah menurut Hayami, (1987)adalah:

1. Membuat arus komoditas yang menunjukkan bentuk-bentuk komoditas, lokasi, lama penyimpanan dan perlakuan yang pernah diberikan kepada komoditas bersangkutan.

2. Mengidentifikasikan setiap transaksi yang terjadi menurut perhitungan finansial.

3. Memilih dasar perhitungan. 
Beberapa variabel yang terkait dalam analisis nilai tambah yaitu:

1. Faktor konversi menunjukkan banyaknya output yang dihasilkan dari satu satuan input.

2. Koefisien tenaga kerja langsung, menunjukkan tenaga kerja langsung yang diperlukan untuk mengolah satu satuan input.

3. Nilai output, menunjukkan nilai ouput yang dihasilkan dari satu satuan input.

Analisis nilai tambah pada subsistem pengolahan, menghasilkan informasi luaran sebagai berikut:

1. Nilai tambah $(\mathrm{Rp})$,

2. Rasio nilai tambah (\%), menunjukkan persentase nilai tambah dari produk,

3. Balas jasa tenaga kerja (Rp), menunjukkan upah yang diterima oleh tenaga kerja langsung untuk memperoleh satu-satuan bahan baku,

4. Bagian tenaga kerja (\%), menunjukkan persentase imbalan tenaga kerja dari nilai tambah,

5. Keuntungan (Rp), menunjukkan bagian yang diterima oleh pemilik faktor produksi karena menanggung risiko usaha,

6. Tingkat keuntungan (\%), menunjukkan persentase keuntungan terhadap nilai tambah,

7. Marjin menunjukkan besarnya kontribusi pemilik faktor produksi selain bahan baku yang digunakan dalam proses produksi.

Tabel 1. Analisis Nilai Tambah Metode Hayami

\begin{tabular}{|c|c|c|}
\hline \multicolumn{3}{|c|}{ Output, Input dan Harga } \\
\hline 1 & Output (Kg/Periode) & A \\
\hline 2 & Bahan Baku (Kg/Periode) & B \\
\hline 3 & Tenaga Kerja (HOK/periode) & $\mathrm{C}$ \\
\hline 4 & Faktor Konversi (Kg Output/Kg Bahan Baku) & $\mathrm{D}=\mathrm{A} / \mathrm{B}$ \\
\hline 5 & Koefisien Tenaga Kerja (HOK/Kg Bahan Baku) & $\mathrm{E}=\mathrm{C} / \mathrm{B}$ \\
\hline 6 & Harga Output $(\mathrm{Rp} / \mathrm{Kg})$ & $\mathrm{F}$ \\
\hline 7 & Upah Rata-rata Tenaga Kerja ( Rp/HOK) & G \\
\hline \multicolumn{3}{|c|}{ Pendapatan dan Keuntungan } \\
\hline 8 & Harga Bahan Baku (Rp/Kg) & $\mathrm{H}$ \\
\hline 9 & Sumbangan Input Lain $((\mathrm{Rp} / \mathrm{Kg})$ & I \\
\hline 10 & Nilai Output (Rp/Kg) & $J=D x F$ \\
\hline 11.a. & Nilai Tambah $(\mathrm{Rp} / \mathrm{Kg})$ & $\mathrm{K}=\mathrm{J}-\mathrm{I}-\mathrm{H}$ \\
\hline b. & Rasio Nilai Tambah (\%) & $\mathrm{L}=(\mathrm{K} / \mathrm{J}) \times 100 \%$ \\
\hline 12.a. & Imbalan Tenaga Kerja (Rp/Kg) & $\mathrm{M}=\mathrm{ExG}$ \\
\hline b. & Bagian Tenaga Kerja (\%) & $\mathrm{N} \%=(\mathrm{M} / \mathrm{K}) \times 100 \%$ \\
\hline 13.a. & Keuntungan $(\mathrm{Rp} / \mathrm{Kg})$ & $\mathrm{O}=\mathrm{K}-\mathrm{M}$ \\
\hline b. & Tingkat Keuntungan (\%) & $\mathrm{P} \%=(\mathrm{O} / \mathrm{J}) \times 100 \%$ \\
\hline \multicolumn{3}{|c|}{ Balas Jasa dari Masing-masing Faktor Produksi } \\
\hline 14.a. & Marjin $(\mathrm{Rp} / \mathrm{Kg})$ & $\mathrm{Q}=(\mathrm{J}-\mathrm{H})$ \\
\hline b. & Imbalan Tenaga Kerja (\%) & $\mathrm{R} \%=(\mathrm{M} / \mathrm{Q}) \times 100 \%$ \\
\hline c. & Sumbangan Input Lain (\%) & $\mathrm{S} \%=(\mathrm{I} / \mathrm{Q}) \times 100 \%$ \\
\hline d. & Keuntungan $(\%)$ & $\mathrm{T} \%=(\mathrm{O} / \mathrm{Q}) \times 100 \%$ \\
\hline 15 & $\mathrm{RC}$ rasio & $\mathrm{U}=\mathrm{J} /(\mathrm{H}+\mathrm{I}+\mathrm{M})$ \\
\hline
\end{tabular}

\section{HASIL DAN PEMBAHASAN}

Rantai Nilai. Rantai distribusi jeruk keprok Soe seperti pada Gambar 1 di bawah ini, antara lain stakeholders jeruk keprok Soe terdiri dari petani, pedagang pengumpul, pedagang pengecer dan konsumen akhir.

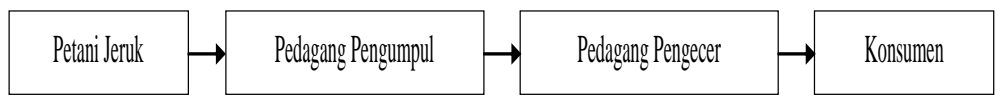

Gambar 1. Rantai Distribusi Jeruk Keprok Soe

Sumber : Hasil Penelitian 
Analisis rantai nilai pascapanen telah dilakukan dengan menggunakan metode Hayami yang menunjukkan marjin, nilai tambah dan keuntungan setiap stakeholder dalam rantai distribusi jeruk keprok Soe dari petani, pedagang pengumpul dan pedagang pengecer, seperti pada tabel berikut :

Tabel 2. Analisis Nilai Tambah Jeruk Keprok Soe

\begin{tabular}{|c|c|c|c|c|}
\hline \multirow[t]{2}{*}{ No } & \multirow[t]{2}{*}{ Uraian } & \multicolumn{3}{|c|}{ Jeruk Keprok Soe } \\
\hline & & Petani & Pengumpul & Pengecer \\
\hline \multicolumn{5}{|c|}{ Output, Input dan Bahan Baku } \\
\hline 1 & Output (Kg/Periode) & 50000 & 50000 & 50000 \\
\hline 2 & Bahan Baku (Kg/Periode) & 50000 & 50000 & 50000 \\
\hline 3 & Tenaga Kerja (HOK/periode) & 69.120 & 23.040 & 23.040 \\
\hline 4 & Faktor Konversi (Kg Output/Kg Bahan Baku) & 1 & 1 & 1 \\
\hline 5 & Koefisien Tenaga Kerja (HOK/Kg Bahan Baku) & 1,38 & 0,46 & 0,46 \\
\hline 6 & Harga Output $(\mathrm{Rp} / \mathrm{Kg})$ & 15000 & 22250 & 35000 \\
\hline 7 & Upah Rata-rata Tenaga Kerja ( Rp/HOK) & 321,18 & 963,54 & 963,54 \\
\hline \multicolumn{5}{|c|}{ Pendapatan dan Keuntungan } \\
\hline 8 & Harga Bahan Baku (Rp/Kg) & 12750 & 16500 & 23750 \\
\hline 9 & Sumbangan Input Lain $((\mathrm{Rp} / \mathrm{Kg})$ & 0 & 0 & 0 \\
\hline 10 & Nilai Output $(\mathrm{Rp} / \mathrm{Kg})$ & 15000 & 22250 & 35000 \\
\hline $11 \mathrm{a}$ & Nilai Tambah $(\mathrm{Rp} / \mathrm{Kg})$ & 2250 & 5750 & 11250 \\
\hline $\mathrm{b}$ & Rasio Nilai Tambah (\%) & 0,150 & 0,258 & 0,321 \\
\hline $12 \mathrm{a}$ & Imbalan Tenaga Kerja (Rp/Kg) & 444 & 444 & 444 \\
\hline $\mathrm{b}$ & Bagian Tenaga Kerja $(\%)$ & 0,20 & 0,08 & 0,04 \\
\hline $13 \mathrm{a}$ & Keuntungan (Rp/Kg) & 1806 & 5306 & 10806 \\
\hline $\mathrm{b}$ & Tingkat Keuntungan $(\%)$ & 0,12 & 0,24 & 0,31 \\
\hline \multicolumn{5}{|c|}{ Balas Jasa dari Masing-masing Faktor Produksi } \\
\hline $14 \mathrm{a}$ & Marjin $(\mathrm{Rp} / \mathrm{Kg})$ & 2250 & 5750 & 11250 \\
\hline $\mathrm{b}$ & Imbalan Tenaga Kerja (\%) & 0 & 0 & 0 \\
\hline $\mathrm{c}$ & Sumbangan Input Lain (\%) & 0 & 0 & 0 \\
\hline $\mathrm{d}$ & Keuntungan (\%) & 0,80 & 0,92 & 0,96 \\
\hline 15 & $\mathrm{RC}$ rasio & 1,14 & 1,31 & 1,45 \\
\hline
\end{tabular}

Sumber: Hasil Penelitian

Hasil analisis rantai nilai menunjukkan bahwa tingkat keuntungan pada pedagang pengumpul sebesar Rp 5.306 per kg, dan pada pedagang pengecer mencapai Rp 10.806 per $\mathrm{kg}$, sedangkan bila dibandingkan dengan keuntungan petani sebagai produsen hanya sebesar Rp 1.806 per $\mathrm{kg}$. Apabila dihitung selisih keuntungan antara setiap pelaku dalam rantai distribusi produk jeruk keprok Soe, maka petani yang merupakan produsen dan sebagai hulu alir produk tersebut hanya menerima nilai tambah sebesar Rp 2.250 per $\mathrm{kg}$, sedangkan pedagang pengumpul menerima nilai tambah sebesar Rp 5.750 per $\mathrm{kg}$ dan pedagang pengecer menerima nilai tambah sebesar Rp 11.250 per kg. RC rasio yang dihasilkan yaitu 1,14 pada tingkat petani, 1,31 pada tingkat pedagang pengumpul dan 1,45 pada tingkat pedagang pengecer.

Pedagang pengumpul mendistribusikan jeruk keprok Soe kepada pedagang pengecer dengan komponen biaya yang dikeluarkan berupa biaya sewa lapak untuk penampungan dan biaya tenaga kerja untuk proses jual beli ke pedagang pengecer. Selama penjualan jeruk di pasar rakyat terdapat susut renstan yang merupakan susut yang terjadi karena penyimpanan di pasar selama jeruk tersebut belum dibeli oleh pedagang pengecer. Kondisi pasar yang tidak terkendali RH dan suhu dapat menyebabkan susut bobot tersebut. Menurut Rustini S, (2011), kenaikan susut bobot dapat disebabkan kelembaban (RH) lingkungan dan suhu serta lama penyimpanan. Berdasarkan biaya, harga dan susut yang terjadi di pasar rakyat dan dihitung menggunakan Hayami, pedagang pengumpul mendapatkan keuntungan sebesar Rp 5.306 per kg, dan pada pedagang pengecer mencapai $\mathrm{Rp} 10.806$ per kg, sedangkan bila dibandingkan dengan keuntungan petani sebagai produsen hanya sebesar Rp 1.806 per $\mathrm{kg}$. 
Hasil analisis rantai nilai pascapanen produk jeruk keprok Soe, bahwa keuntungan pascapanen petani jauh lebih rendah daripada pedagang pengumpul dan pedagang pengecer di pasar rakyat. Hal ini dapat disebabkan oleh rendahnya harga yang diterima petani, hanya sebesar Rp 15.000 per kg karena sedang pada musim panen raya. Nilai RC rasionya pun lebih rendah dibandingkan dengan pelaku lainnya, petani memiliki $\mathrm{RC} 1,14$, pedagang pengumpul memiliki RC hingga 1,31 dan pedagang pengecer memiliki RC mencapai 1,45. Nilai RC lebih dari satu menujukkan bahwa petani, pedagang pengumpul dan pedagang pengecer di pasar rakyat tidak mengalami kerugian. Namun demikian, salah satu ukuran perdagangan yang adil dapat ditunjukkan degan RC yang hampir sama sepanjang rantai distribusi produk tersebut. Menurut Dirjen P2HP (Direktorat Jenderal Pengolahan dan Pemasaran Hasil Pertanian, 2006) tata niaga produk-produk pertanian umumnya masih dikuasai oleh tengkulak/pedagang perantara antara lain pedagang pengumpul maupun pedagang pengecer sehingga marjin petani relatif lebih kecil dibandingkan dengan para pelaku lainnya. Hal senada disampaikan oleh Mayrowani et al (2013); Analianasari dan Marlinda, (2018) menemukan bahwa yang menerima marjin keuntungan terbesar dalam pemasaran produk-produk pertanian dari pusat produksi ke pusat konsumsi adalah pedagang perantara baik pedagang pengumpul, pedagang pengirim maupun pedangan pengecer di pasar akhir. Triyono et al , (2010), petani selalu mendapatkan keuntungan kecil dibandingkan pelaku lainnya, ditunjukkan dengan farmer share petani yang lebih rendah. Pada saat tidak pada masa panen raya, tingginya harga produk-produk pertanian di tingkat pengecer dan pasar akhir tidak terdistribusi dengan baik ke tingkat petani sehingga petani mendapatkan bagian kecil dan fluktuatif.

Analisis Biaya Pokok Penyimpanan Dingin. Penerapan teknologi penyimpanan dingin dapat meningkatkan nilai tambah petani karena melakukan penundaan penjualan sampai harga kembali naik dengan susut yang rendah selama penundaan tersebut. Pengaturan pasokan oleh petani ke pasar menjadi penting untuk mengendalikan harga sehingga petani terhindar dari harga rendah dan memperoleh peningkatan keuntungan terutama di masa panen raya. Mutia et all (2017) menyatakan bahwa penyimpanan dingin temperatur hanya mengalami susut berat 3,5-12\% selama penyimpanan 2 bulan. Prinsip dari perlakuan penyimpanan dingin adalah mengendalikan laju transpirasi, mengendalikan respirasi, mengendalikan/mencegah serangan penyakit, mencegah perubahan-perubahan yang tidak dikehendaki konsumen. Selama penyimpanan 2 bulan tersebut dapat terjadi peningkatan harga produk sehingga keuntungan petani bertambah. Namun demikian, perlu ada analisis kelayakan operasional melalui biaya pokok karena investasi penyimpanan dingin sangat tinggi.

Penyimpanan dingin yang menjadi objek kajian merupakan bantuan pemerintah yang dikelola oleh Koperasi Lais Manekat. Spesifikasi umum terdiri dari kapasitas 400 ton dengan dimensi luas 30x25 meter dan mampu mempertahankan suhu 5-10 $\mathrm{C}$. Gambar 2 berikut menampilkan tampak luar gudang penyimpanan jeruk keprok Soe yang di dalamnya terdapat coldstorage

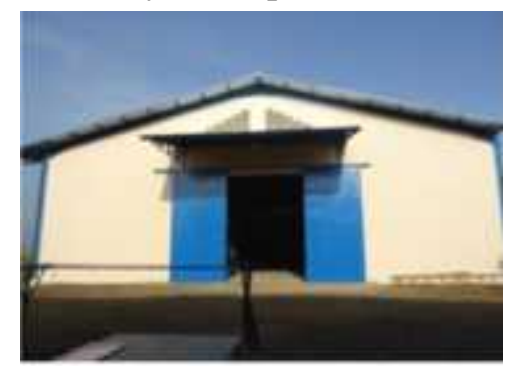

Gambar 2. Bangunan Luar Gudang Penyimpanan Jeruk Keprok Soe Berpendingin

Gudang tersebut dilengkapi oleh tiga ruangan. Ruangan pertama digunakan untuk proses pembersihan dan sortasi buah. Ruangan kedua disebut dengan anteroom untuk ruangan precooling sebelum jeruk keprok Soe dimasukan ke dalam coldroom (suhu 10-15 ${ }^{\circ} \mathrm{C}$ ). Ruangan ketiga coldroom untuk penyimpanan dingin 
jeruk keprok Soe (suhu 0-5 ${ }^{\circ} \mathrm{C}$ ). Gambar 3 berikut menampilkan tataletak gudang penyimpanan jeruk keprok Soe berpendingin.

Gambar 3. Tata letak Ruang Pendingin

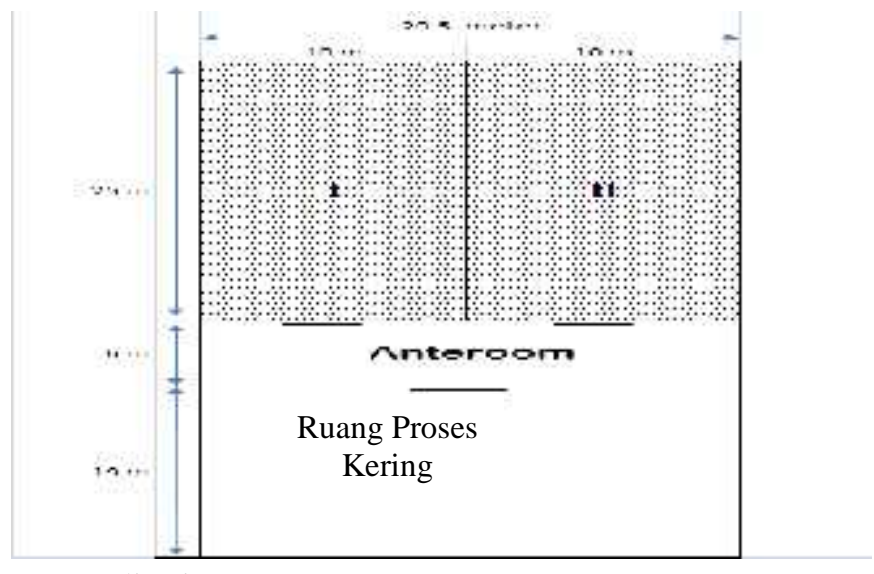

Coldstorage dibagi menjadi 3 komponen utama yaitu mesin pendingin, bahan isolasi ruangan dan generator. Gambar 4, 5 dan 6 menampilkan ketiga komponen tersebut. Berikut spesifikasi detail ketiga komponen coldstorage.

Mesin Pendingin $\left(+5^{\circ} \mathrm{C}\right.$ )

Spesifikasi yang ada adalah sebagai berikut :

Compressor : unit open 4G.2 HP - Merk Bitzer

Condensor : unit Air Cooled Condenser Greenhalgh

Evaporator : unit Air Cooled Evaporator Muller

Aksesoris : Check valve, Oil separator, Receiver tank, Filter Drier, Sight Glass, Liquid Solenoid, Valve, Stop kran, Expansion Valve, HLP, chasis, Suctionmeter, ressmeter dan electromotor.

Panel listrik box : MCB, Overload \& phase digital thermostat

Refrigerant : R 22

Power : $380 \mathrm{~V} / 3$ phase / $50 \mathrm{~Hz}$

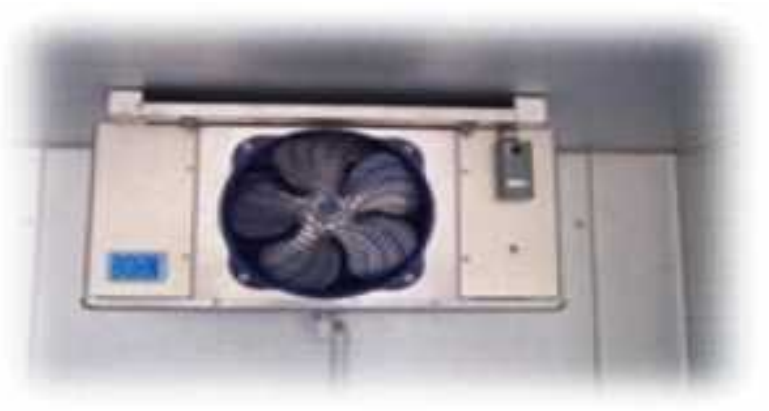

Gambar 4. Komponen Mesin Pendingin

Spesifikasi Komponen Isolasi Ruangan :

Isolasi Dinding/ Atap

Density $\quad: 45 \mathrm{Kg} / \mathrm{m}^{3} \pm 5 \%$

Isolasi $\quad: 0.4 \mathrm{~mm}$ PPGI mengapit $75 \mathrm{~mm}$ polyurethane foa

Join system : semi CamLock

Isolasi Lantai

- Konstruksi lapisan lantai (dari atas ke bawah)

- $75 \mathrm{~mm}$ cor beton bertulang

- Aluminium foil 2 sisi sebagai Vapor Barrier dan perekat foil tape

- $75 \mathrm{~mm}$ polyurethane foam, density $45 \mathrm{Kg} / \mathrm{m}^{3} \pm 5 \%$ 
- Lapisan water proofing

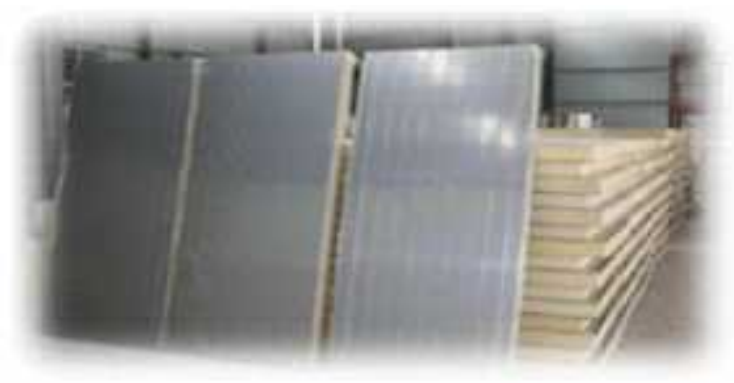

Gambar 5. Komponen Material Ruangan

\section{Generator (Genset)}

Genset diperlukan sebagai cadangan sumber listrik ketika aliran listrik dari PLN terputus. Spesifikasi genset sebagai berikut :

- Kapasitas : $250 \mathrm{kVA}$

- Model : Open Type / $1500 \mathrm{rpm}$

- Voltage : $230 \mathrm{~V} / 380$ Volt, 3 Phase 4 Wire, $50 \mathrm{~Hz}, \mathrm{I}$

- Power Factor: 0.8

- Starter : Electrical Starting

- Pendinginan: Radiator Cooled

- Perlengkapan: Generator control panel, exhaust flexible pipe, exhaust silencer, battery set, daily tank, safety device/ automatic shut down

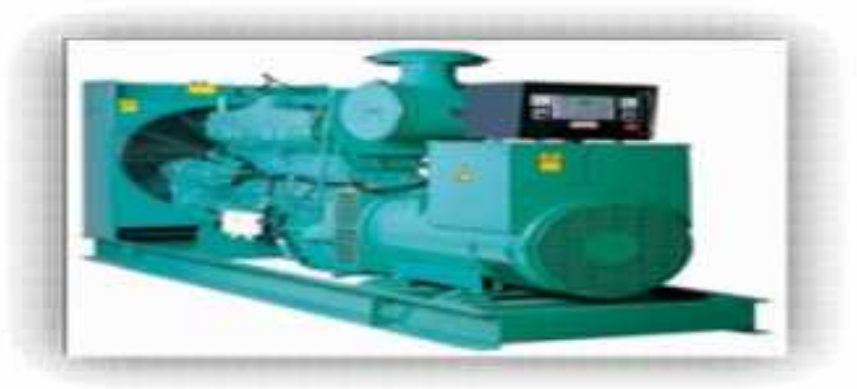

Gambar 6. Komponen Genset

Berdasarkan hasil wawancara mendalam dengan pengurus koperasi diperoleh data biaya tetap dan harga perolehan pendirian coldstorage.

Tabel 3. Biaya Tetap Penyimpanan Dingin

\begin{tabular}{lrcrr}
\hline \multicolumn{1}{c}{ Keterangan } & \multicolumn{1}{c}{$\begin{array}{c}\text { Nilai } \\
\text { Investasi }\end{array}$} & $\begin{array}{c}\text { Umur Ekonomis } \\
\text { (Tahun) }\end{array}$ & $\begin{array}{c}\text { Biaya } \\
\text { Penyusutan } \\
\text { Tahunan }\end{array}$ & $\begin{array}{c}\text { Biaya } \\
\text { Bunga/Tahun } \\
(10 \%)\end{array}$ \\
\hline 1. Bangunan & 1.232 .000 .000 & 20 & 61.600 .000 & 64.680 .000 \\
2. Cold Storage & 2.975 .329 .800 & 20 & 148.766 .490 & 156.204 .815 \\
3. Genset & 250.000 .000 & 5 & 50.000 .000 & 15.000 .000 \\
4. Kabel Listrik & 3.750 .000 & 5 & 750.000 & 225.000 \\
5. Lampu & 7.500 .000 & 5 & 1.500 .000 & 450.000 \\
6. Stop kontak & 4.500 .000 & 5 & 900.000 & 270.000 \\
7. Gudang Peralatan & 292.000 .000 & 20 & 14.600 .000 & 15.330 .000 \\
8. Rak Penyimpanan & 1.800 .000 .000 & 20 & 90.000 .000 & 94.500 .000 \\
9. Kipas & 20.000 .000 & 5 & 4.000 .000 & 1.200 .000 \\
10. Fork Klip & 400.000 .000 & 20 & 20.000 .000 & 21.000 .000 \\
\hline Sur
\end{tabular}

Sumber : Hasil Penelitian 
Berdasarkan tabel tersebut di atas, biaya terbesar adalah biaya pendirian bangunan sebesar Rp 1.232.000.000 dan coldstorage sebesar Rp 2.975.329.800. total kedua biaya investasi tersebut mencapai $\mathrm{Rp}$ 4.207.329.800. Walaupun sumber listrik utama dari PLN, namun fasilitas coldstorage dilengkapi oleh genset untuk antisipasi ketiadaan sumber listrik dari PLN sehingga suhu coldstorage dapat dijaga. Menurut Aung MM, (2014) pengendalian dan manajemen temperatur yang baik merupakan hal yang krusial untuk produk perishabel dan menjamin aman untuk dikonsumsi.

Biaya tetap yang dihitung adalah biaya penyusutan dan biaya bunga modal. Pada tabel di atas menunjukkan bahwa biaya penyusutan paling besar yaitu coldstorage dan pendirian bangunan. Pendirian bangunan diperlukan untuk melindungi coldstorage dari cuaca agar umur ekonomisnya dapat maksimal. Nilai penyusutan dihitung menggunakan metode garis lurus. Perhitungan penyusutan dengan metode garis lurus telah dilakukan oleh Islam, Kabir, \& Kabir, (2008) untuk menghitung depresiasi coldstorage milik pribadi dan milik pemerintah. Dengan metode garis lurus tersebut, persentase penyusutan bergantung umur ekonomis, bila umur ekonomisnya 20 tahun maka persentase penyusutannya seperduapuluh atau 5\% per tahun. Investasi bangunan, coldstorage, gudang peralatan, rak penyimpanan dan forklip memiliki umur ekonomis 20 tahun sehingga nilai penyusutannya 5\% per tahun. Hal ini pun dinyatakan oleh Kart MCO, (2014) bahwa penyusutan bangunan dan coldstorage antara 2 sampai dengan 6\%. Sedangkan untuk bahanbahan plastik seperti peralatan kabel, lampu dan kipas memiliki umur ekonomis selama 5 tahun sehingga nilai penyusutan $20 \%$ per tahun. Kart MCO, (2014) pun menyatakan bahwa nilai penyusutan untuk peralatan pembantu dan berbahan plastik berkisar antara 14 sampai dengan $20 \%$ per tahun.

Nilai bunga $10 \%$ per tahun sebagai acuan untuk menentukan biaya bunga modal. Islam et al., (2008) menggunakan bunga modal sebesar $10 \%$ dari harga pembelian coldstorage. Kart MCO, (2014) menyatakan bahwa bunga modal dan pajak hanya mencapai $4 \%$ setiap tahunnya.

Komponen biaya tidak tetap terdiri dari tenaga kerja, bahan bakar, pemelliharaan dan biaya listrik. Biaya tidak tetap yang dikeluarkan bergantung dari lama operasional coldstorage yang dihitung dalam satuan waktu bulanan karena biaya sewa yang dikenakan kepada petani dalam satuan bulanan. Tenaga kerja coldstorage terdiri dari tenaga kerja tetap sebanyak 4 orang dengan upah Rp 1.500 .000 setiap orangnya per bulan, sedangkan tenaga kerja borongan maksimal sebanyak 10 orang dengan biaya Rp 650.000 per orang setiap bulan. Solar Genset hanya digunakan bila mengalami gangguan listrik, terlihat bahwa biaya operasional terbesar adalah biaya listrik (Tabel 4). Menurut Kart MCO, (2014) biaya tidak tetap terbesar coldstorage adalah listrik, bahan bakar dan oli.

Tabel 4. Biaya-biaya Tidak Tetap Penyimpanan Dingin

\begin{tabular}{lr}
\hline \multicolumn{1}{c}{ Keterangan } & $\begin{array}{c}\text { Biaya Per Bulan } \\
(\mathrm{Rp})\end{array}$ \\
\hline Tenaga Tetap & 6.000 .000 \\
Tenaga Borongan & 6.500 .000 \\
Solar Genset dan Pemeliharaan & 2.300 .000 \\
Solar Forklip dan Pemeliharaan & 1.800 .000 \\
Biaya listrik & 13.000 .000 \\
Biaya Tidak Tetap (Rp/bulan) & $\mathbf{2 9 . 6 0 0 . 0 0 0}$ \\
\hline
\end{tabular}

Sumber : Hasil Penelitian

Biaya total (B) coldstorage merupakan biaya keseluruhan yang diperlukan untuk mengoperasikan coldstorage, asumsi operasional coldstorage selama 1`kali masa simpan dalam setahun adalah 3 bulan. Lama operasional tersebut sangat rendah bila dibandingkan dengan penelitian Islam et al., (2008) yang menunjukkan bahwa coldstorage di Bangladesh mempunyai lama operasional hingga 9 bulan. Hal ini karena coldstorage objek penelitan hanya digunakan untuk jeruk keprok Soe sedangkan di Bangladesh dapat 
digunakan untuk jenis komoditas lainnya. Biaya total dapat dilihat pada Tabel 5 berikut, dimana tabel tersebut menunjukkan bahwa biaya tetap lebih besar dibandingkan dengan biaya tidak tetap. Sebesar 89,5\% dari biaya total merupakan biaya tetap sedangkan biaya tidak tetap sebesar $10,5 \%$ dari biaya total. Sedangkan menurut Kart MCO, (2014) biaya tetap sebesar 60\% dan biaya tidak tetap sebesar $40 \%$. Perbedaan ini karena nilai bunga yang diasumsikan lebih tinggi dibandingkan dengan kajian Kart MCO, (2014) yang hanya sebesar 4\% per tahun.

Tabel 5. Data Perhitungan Biaya Total Penyimpanan Dingin

\begin{tabular}{lrr}
\hline \multicolumn{1}{c}{ Keterangan } & \multicolumn{1}{c}{ Nilai } & \multicolumn{1}{c}{$\%$} \\
\hline Biaya Tetap Penyusutan(Rp/bulan) & 130.705 .497 & 46,14 \\
Biaya Tetap Bunga modal(Rp/bulan) & 122.953 .271 & 43,40 \\
Biaya Tidak tetap (Rp/bulan) & 29.600 .000 & 10,46 \\
Biaya Total (Rp/bulan) & $\mathbf{2 8 3 . 2 5 8 . 7 6 8}$ & 100 \\
\hline Sumber :Hasil Penelitian & &
\end{tabular}

Besarnya biaya tetap dan biaya tidak tetap dalam pembangunan dan operasional coldstorage jeruk keprok Soe menyebabkan Koperasi Lais Manekat dibantu oleh pemerintah provinsi, coldstorage akan memberikan manfaat sosial ekonomi secara berkelanjutan dengan mempertimbangkan keterlibatan pemerintah daerah dan pelaku bisnis untuk melakukan sharing modal. Perhitungan biaya pokok menggunakan persamaan [2]. Asumsi pada perhitungan ini adalah lama operasional 3 bulan per tahun dan bunga modal sebesar $10 \%$ serta kapasitas penuh terpakai.

$$
B p=\frac{R p 283.258 .768 \text { per bulan }}{400.000 \mathrm{~kg}}=\mathrm{Rp} 708,146 \text { per bulan } \text { per } \mathrm{kg}
$$

Dari hasil perhitungan di atas dapat disimpulkan bahwa biaya sewa minimal agar koperasi tidak mengalami kerugian dalam operasional coldstorage adalah Rp 708,146 per bulan per kg. Nilai tersebut lebih tinggi dibandingkan hasil penelitian Kart dan Demircan (2014) yang menunjukkan bahwa biaya pokok sebesar \$ 0.023 per kg atau setara dengan Rp 322 per kg (kurs \$ 1 setara dengan Rp. 14.000). Tingginya biaya pokok karena kapasitas 400 ton sedangkan penelitian Kart dan Demircan (2014) kapasitasnya mencapai 5.000 ton. Gambar 7 berikut ini menampilkan perubahan biaya pokok terhadap perubahan asumsi.
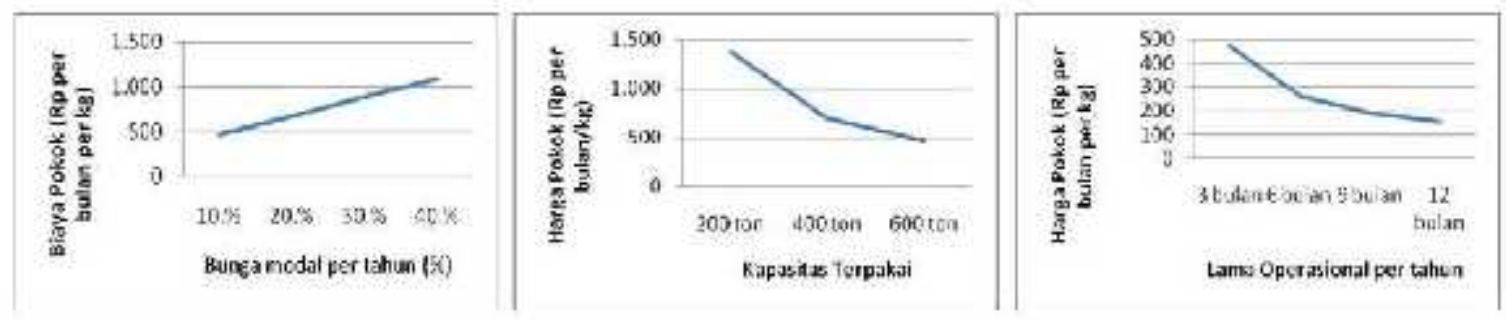

Gambar 7. Perubahan Biaya Pokok Terhadap Perubahan Asumsi Bunga Modal (a), Kapasitas Terpakai (b) dan Lama Operasional (c)

Berdasarkan kurva pada gambar 7a di atas, pada asumsi lama operasional tetap selama 3 bulan dan kapasitas terpakai 400 ton, biaya pokok semakin meningkat seiring dengan peningkatan bunga modal. Terlihat bahwa perubahan bunga modal dari $10 \%$ menjadi $40 \%$ akan meningkatkan biaya pokok dari Rp 708,146 menjadi Rp 1.087 per kg per bulan. 
Gambar 7b menunjukkan bahwa pada bunga modal tetap 10\% dan lama operasional 3 bulan pertahun, terjadi penurunan biaya pokok seiring dengan peningkatan kapasitas terpakai. Perubahan kapasitas akan mempengaruhi biaya tidak tetap saja karena coldstorage sudah dimiliki oleh Koperasi Lais Manekat. Dari kurva di atas, peningkatan kapasitas terpakai penyimpanan dari 200 ton menjadi 400 ton akan menurunkan biaya pokok dari Rp 1.372 menjadi Rp 708,146 per kg per bulan.

Biaya pokok akan berubah bergantung pada jam kerja operasional pemakaian coldstorage. Dari gambar 7c, semakin sering coldstorage dipakai maka semakin rendah biaya pokok produksinya. Peningkatan bulan operasional coldstorage dari 3 bulan per tahun menjadi 12 bulan pertahun akan menurunkan biaya pokok dari Rp 708,146 menjadi Rp 155 per bulan per tahun. Upaya-upaya peningkatan kapasitas terpakai dan jam kerja operasional coldstorage yaitu penerapan sistem rotasi tanam maupun panen jeruk keprok Soe dan kerjasama dengan pelaku komoditi selain jeruk keprok Soe yang membutuhkan penyimpanan dingin.

Nilai Tambah Penyimpanan Dingin. Nilai tambah merupakan salah satu komponen dalam membentuk nilai jual produk, sedangkan nilai produk merupakan nilai yang dimiliki sebuah produk dan terdiri dari nilai tambah pengolahan, nilai bahan baku, dan nilai input lainnya (Dilana 2013). Peningkatan nilai sebagai akibat pengurangan susut selama penyimpanan dengan menggunakan teknologi penyimpanan dingin. Tabel berikut menunjukkan perbandingan nilai tambah penyimpanan dingin dengan penyimpanan konvensional yang dilakukan selama ini.

Biaya pokok digunakan untuk menghitung nilai tambah penyimpanan dingin. Biaya pokok tersebut dalam metode hayami sebagai sumbangan input lain. Perbandingan nilai tambah penyimpanan dingin dapat dilihat pada Tabel 6 berikut.

Tabel 6. Perbandingan Nilai Tambah Penyimpanan Dingin

\begin{tabular}{|c|c|c|c|}
\hline No & Uraian & $\begin{array}{l}\text { Penyimpanan } \\
\text { Konvensional }\end{array}$ & $\begin{array}{c}\text { Teknologi } \\
\text { Penyimpanan } \\
\text { Dingin }\end{array}$ \\
\hline \multicolumn{4}{|c|}{ Output, Input dan Bahan Baku } \\
\hline 1 & Output (Kg/Periode) & 50000 & 50000 \\
\hline 2 & Bahan Baku (Kg/Periode) & 50000 & 50000 \\
\hline 3 & Tenaga Kerja (HOK/periode) & 13542 & 13542 \\
\hline 4 & Faktor Konversi (Kg Output/Kg Bahan Baku) & 1,00 & 1,00 \\
\hline 5 & Koefisien Tenaga Kerja (HOK/Kg Bahan Baku) & 0,271 & 0,271 \\
\hline 6 & Harga Output $(\mathrm{Rp} / \mathrm{Kg})$ & 15000 & 22250 \\
\hline 7 & Upah Rata-rata Tenaga Kerja ( Rp/HOK) & 30000 & 30000 \\
\hline \multicolumn{4}{|c|}{ Pendapatan dan Keuntungan } \\
\hline 8 & Harga Bahan Baku (Rp/Kg) & 12750 & 12750 \\
\hline 9 & Sumbangan Input Lain $((\mathrm{Rp} / \mathrm{Kg})$ & 1372 & 708,146 \\
\hline 10 & Nilai Output $(\mathrm{Rp} / \mathrm{Kg})$ & 22250 & 35000 \\
\hline $11 \mathrm{a}$ & Nilai Tambah $(\mathrm{Rp} / \mathrm{Kg})$ & 8128 & 21542 \\
\hline $\mathrm{B}$ & Rasio Nilai Tambah (\%) & 0,365 & 0,615 \\
\hline $12 \mathrm{a}$ & Imbalan Tenaga Kerja $(\mathrm{Rp} / \mathrm{Kg})$ & 8125 & 8125 \\
\hline $\mathrm{B}$ & Bagian Tenaga Kerja $(\%)$ & 1000 & 0,377 \\
\hline $13 \mathrm{a}$ & Keuntungan $(\mathrm{Rp} / \mathrm{Kg})$ & 3000 & 13417 \\
\hline $\mathrm{b}$ & Tingkat Keuntungan $(\%)$ & 0,001 & 0,383 \\
\hline \multicolumn{4}{|c|}{ Balas Jasa dari Masing-masing Faktor Produksi } \\
\hline $14 \mathrm{a}$ & Marjin $(\mathrm{Rp} / \mathrm{Kg})$ & 9500 & 22250 \\
\hline $\mathrm{b}$ & Imbalan Tenaga Kerja (\%) & 0,855 & 0,365 \\
\hline $\mathrm{c}$ & Sumbangan Input Lain (\%) & 0,144 & 0,032 \\
\hline $\mathrm{d}$ & Keuntungan (\%) & 0,003 & 0,063 \\
\hline 15 & $\mathrm{RC}$ rasio & 1,00 & 1,62 \\
\hline
\end{tabular}

Sumber : Hasil Penelitian 
Berdasarkan analisis biaya pokok, penyimpanan dingin selama 3 bulan membutuhkan biaya sebesar Rp 708,146 per kg. Nilai tersebut lebih rendah dibandingkan dengan penyimpanan konvensional sebesar Rp 1.372 per kg. Berdasarkan wawancara mengenai prediksi harga 3 bulan ke depan dan nilai susut terdapat perbedaan signifikan antara penyimpanan konvensional dengan penyimpanan dingin. Keuntungan penyimpanan dingin lebih besar dari pada penyimpanan konvensional, yaitu memperoleh keuntungan Rp 13.417 per kg selama penyimpanan 3 bulan sedangkan penyimpanan konvensional $\mathrm{Rp} 3.000$ per $\mathrm{kg}$. Peningkatan tersebut diperoleh dengan asumsi harga sebelum disimpan Rp 22.250 per $\mathrm{kg}$, dan harga jual setelah disimpan Rp 35.000 per kg.

Sidhu, Kumar,et al (2010) menambahkan bahwa untuk meningkatkan nilai tambah dengan penurunan susut perlu kerjasama pemasaran dengan supermarket karena dilengkapi oleh fasilistas precooling, transportasi berpendingin serta adanya ruangan berpendingin di outlet-outletnya. Namun demikian, aktivitas integrasi pasar dan kerjasama supermarket tidak bisa dilakukan oleh individu petani jeruk keprok Soe karena skalanya kecil. Koperasi menjadi solusi karena mampu menghimpun jeruk keprok dan memasarkan agar terjamin kualitas, kuantitas dan kontinuitas pengiriman produk ke berbagai supermarket.

Tingginya nilai tambah penyimpanan dingin merupakan peluang bagi stakeholders untuk mencegah kerugian dari penurunan harga dan susut penyimpanan konvensional. Analisis rantai nilai menunjukkan ada tiga stakeholder yang dapat menggunakan teknologi penyimpanan dingin yaitu petani, pedagang pengumpul dan pedagang pengecer di beberapa pasar rakyat di Kota Kupang. Dengan keuntungan dan nilai RC yang paling rendah pada petani, teknologi penyimpanan dingin lebih sesuai untuk petani dibandingkan dengan pelaku lainnya. Namun demikian biaya total penyimpanan dingin yang tinggi (Tabel 5) dan disertai dengan jumlah panen petani yang sangat rendah, teknologi penyimpanan dingin perlu dikelola oleh koperasi petani. Hasil penelitian Ito, Bao, \& Su, (2012) menunjukkan bahwa sistem koperasi merupakan sarana penting bagi petani kecil untuk meningkatkan pendapatan.

Seringkali permasalahan penyimpanan yang terjadi yaitu ketidakmauan petani menyimpan karena membutuhkan uang tunai untuk sehari-hari dan persiapan musim tanam berikutnya. Beberapa strategi agar petani mau melakukan penyimpanan dingin dengan sosialisasi manfaat penyimpanan dingin terutama nilai tambahnya, memperkuat lembaga koperasi dan mengaplikasikan sistem resi gudang di penyimpanan dingin. Sistem tersebut sangat prospektif terutama pada saat harga sedang anjlok (Bappebti, 2019). Dengan teknologi penyimpanan dingin dan interaksi antar stakeholders, peluang penawaran jeruk keprok Soe akan tetap terkendali.

\section{KESIMPULAN}

Berdasarkan biaya, harga dan susut yang terjadi di pasar rakyat dan dihitung menggunakan Hayami, pedagang pengumpul mendapatkan keuntungan sebesar Rp 5.306 per $\mathrm{kg}$, dan pada pedagang pengecer mencapai Rp 10.806 per kg, sedangkan bila dibandingkan dengan keuntungan petani sebagai produsen hanya sebesar Rp 1.806 per kg.

Berdasarkan analisis biaya pokok, penyimpanan dingin selama 3 bulan membutuhkan biaya sebesar Rp 708,146 per kg. Nilai tersebut lebih rendah dibandingkan dengan penyimpanan konvensional sebesar Rp 1.372 per kg. Berdasarkan wawancara mengenai prediksi harga 3 bulan ke depan dan nilai susut terdapat perbedaan signifikan antara penyimpanan konvensional dengan penyimpanan dingin. Keuntungan penyimpanan dingin lebih besar dari penyimpanan konvensional, yaitu memperoleh keuntungan Rp 13.417 per kg selama penyimpanan 3 bulan sedangkan penyimpanan konvensional Rp. 3000 per kg. Peningkatan tersebut diperoleh dengan asumsi harga sebelum disimpan $\mathrm{Rp} 22.250$ per $\mathrm{kg}$, dan harga jual setelah disimpan Rp 35.000 per kg. 
Tingginya nilai tambah penyimpanan dingin merupakan peluang bagi stakeholders untuk mencegah kerugian dari penurunan harga dan susut penyimpanan konvensional. Analisis rantai nilai menunjukkan ada tiga stakeholder yang dapat menggunakan teknologi penyimpanan dingin yaitu petani, pedagang pengumpul dan pedagang pengecer di beberapa pasar rakyat di Kota Kupang. Dengan keuntungan dan nilai RC yang paling rendah pada petani, teknologi penyimpanan dingin lebih sesuai untuk petani dibandingkan dengan pelaku lainnya. Namun demikian biaya total penyimpanan dingin yang tinggi dan disertai dengan jumlah panen petani yang sangat rendah, teknologi penyimpanan dingin perlu dikelola oleh koperasi petani. Dengan teknologi penyimpanan dingin dan interaksi antar stakeholders, peluang penawaran jeruk keprok Soe akan tetap terkendali.

\section{ACKNOWLEDGMENT}

Peneliti menyampaikan terima kasih kepada Kementerian Riset, Teknologi dan Pendidikan Tinggi, Direktorat Jenderal Penguatan Riset dan Pengembangan, dan Direktorat Penelitian dan Pengabdian Masyarakat yang telah menyetujui dan bersedia membiayai penelitian kompetitif nasional pada skema penelitian dosen pemula tahun 2019 ini. Ucapan terima kasih juga Peneliti sampaikan kepada Pemerintah Kabupaten Timor Tengah Selatan dan semua pihak yang telah membantu dengan caranya masing-masing, untuk kelancaran penyelesaian kegiatan penelitian ini

\section{DAFTAR PUSTAKA}

Analianasari; Marlinda Apriyani (2018) 'Sifat Organoleptik Yogurt Beku', Jurnal Teknologi \& Industri Hasil Pertanian, 24(1), pp. 59-66.

Aung MM, C. Y. (2014) 'Temperature Management for the Quality Assurance of a Perishabel Food Supply Chain', Food Control, 40, pp. 198-207.

Bahtiar J, K. G. (2011) Penerapan Rantai Nilai (Value Chain Analysis) dalam Rangka Akselerasi Pembangunan Sektor Pertanian di Sulawesi Utara. Sulawesi Utara: Balai Pengkajian Teknologi Pertanian (BPTP).

Bappebti (2019) Pedoman Kelompok Tani Sistem Resi Gudang, Kementerian Perdagangan Republik Indonesia. doi: 10.1017/CBO9781107415324.004.

Direktorat Jenderal Pengolahan dan Pemasaran Hasil Pertanian (2006) 'Road map Pascapanen dan Pemasaran Hasil Pertanian', Kementerian Pertanian.

Hayami, Y. et al. (1987) 'Agricultural Marketing and Processing in Upland Java A Perspective From A Sunda Village', Regional Co-ordination Centre for Research and Development of Coarse Grains. Pulses, Roots and Tuber Crops in the Humid Tropics of Asia and the Pacific.

Islam, M. M., Kabir, M. H. and Kabir, M. S. (2008) 'MANAGEMENT PRACTICES IN SOME SELECTED COLD STORAGE IN BANGLADESH', j. innov.dev.strategy . 2(3):48-54, 2(November), pp. 48-54.

Ito, J., Bao, Z. and Su, Q. (2012) 'Distributional effects of agricultural cooperatives in China: Exclusion of smallholders and potential gains on participation', Food Policy. doi: 10.1016/j.foodpol.2012.07.009.

Kart MCO, D. V (2014) 'An Economic Comparison of Conventional and Modern Coldstorage Facilities Turkey’, Universidade Federal Rural de Pernambuco, 10(1).

Kotler, P. \& Armstrong, G. (2008) Prinsip-Prinsip Pemasaran. Edisi 12. Jilid 1., Manajemen Pemasaran. 
Batafor, G. dan Yason : Rantai Nilai J eruk Keprok (citrus reticulate) Soe.

Mayrowani H, Agustin NK, Swastika DK, A. M. (2013) 'Analisis Struktur Perilaku Kinerja Pemasaran Sayuran Bernilai Ekonomi Tinggi’, Laporan Akhir. Pusat Penelitain dan Pengembangan Sosial Ekonomi Pertanian.

Mutia, A. K., Purwanto, Y. A. and Pujantoro, L. (2017) 'Perubahan Kualitas Bawang Merah (Allium Ascalonicum L.) Selama Penyimpanan Pada Tingkat Kadar Air Dan Suhu Yang Berbeda ((Allium ascalonicum 1.) During Storage at Different Temperature and Water Content)', Jurnal Penelitian Pascapanen Pertanian. doi: 10.21082/jpasca.v11n2.2014.108-115.

Rustini S, P. B. (2011) Teknologi Produksi Benih Bawang Merah Varietas Bima Brebes. Risalah Hasil Pengkajian Inovasi Hortikultura di Jawa Tengah. Jawa Tengah: Balai Pengkajian Teknologi Pertanian Jawa Tengah.

Sidhu, R. et al. (2010) 'Supply Chain Analysis of Onion and Cauliflower in Punjab', Agricultural Economics ..., 23(2005), pp. 445-453. Available at: http://ageconsearch.umn.edu/bitstream/96919/2/7-RSSidhu.pdf.

Triyono. Rosyadi, Imron. Fatchan, A. (2010) 'Efisiensi pengelolaan pasar bawang merah di kabupaten brebes', Dinamika Sosial Ekonomi, 6, pp. 1-15. 